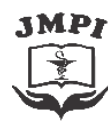

Jurnal Mandala Pharmacon Indonesia, Vol 4.No.1 Juni 2018

Avaiable online at www.jurnal-pharmaconmw.com/jmpi

$p$-ISSN : 2442-6032

$e$-ISSN : 2598-9979

\title{
Uji Daya Hambat Antibakteri Fungi Endofit Daun Beluntas (Pluchea indica (L.) Less.) Terhadap Bakteri Streptococcus mutans
}

\author{
Muhammad Azdar Setiawan, Musdalipah \\ Politeknik Bina Husada Kendari, Program Studi D-III Farmasi
}

\begin{abstract}
ABSTRAK
Karies gigi atau dikenal dengan gigi berlubang merupakan suatu penyakit pada jaringan keras gigi akibat bakteri S. mutans. Salah satu tanaman yang memiliki aktivitas antibakteri terhadap S. mutans yang telah banyak diteliti adalah daun beluntas. Usaha untuk mengurangi eksploitasi alam adalah dengan mengisolasi jamur endofit pada bagian tanaman yang dapat memproduksi senyawa aktif. Jamur endofit merupakan jamur yang hidup pada sistem jaringan tanaman yang tidak menyebabkan gejala penyakit pada tanaman inangnya serta dapat menghasilkan senyawa metabolit sekunder seperti antibakteri, antivirus, antifungi dan sebagainya. Tujuan penelitian ialah untuk mengetahui seberapa besar daya hambat jamur endofit daun beluntas terhadap pertumbuhan bakteri S. mutans. Metode penelitian yang digunakan adalah metode Paper disk. Hasil penelitian diperoleh 2 isolat jamur

endofit daun beluntas yaitu jamur endofit putih dan jamur endofit hitam. Jamur endofit putih menghasilkan zona hambat terhadap bakteri $S$. mutans rata-rata $10 \%=1,15 \mathrm{~mm}, 20 \%=1,51 \mathrm{~mm}$, $30 \%=2,55 \mathrm{~mm}$, kontol positif sebesar 1,28 $\mathrm{mm}$ dan kontrol negatif tidak memberikan zona hambat. Sedangkan jamur endofit hitam daun beluntas tidak memberikan zona hambat.

Kata kunci : Jamur Endofit, Daun Beluntas, Antibakteri.

\section{Penulis Korespondensi:}

Muhammad Azdar Setiawan

Program Studi D-III Farmasi Politeknik Bina

Husada Kendari,

E-mail : musdalipahapt@gmail.com
\end{abstract}

\section{PENDAHULUAN}

Dewasa ini, biaya masalah kesehatan semakin meningkat sejalan dengan perkembangan penyakit. (Musdalipah, dkk, 2018). Salah satunya ialah karies gigi. Karies gigi atau dikenal dengan gigi berlubang adalah suatu penyakit pada jaringan keras gigi yang sudah dikenal umum oleh masyarakat.(Nahak, M. 2012). Karies terjadi akibat proses demineralisasi permukaan email yang disebabkan oleh asam yang diproduksi oleh bakteri dalam plak utamanya yaitu Streptococcus mutans dan mungkin juga oleh Lactobacillus.(Lewis dkk, M. 2012 ).

Penyebab utama dari karies gigi adalah penumpukan plak gigi yang banyak mengandung bakteri (Daud, dkk, 2016). Beragam cara dilakukan untuk mencegah penyebab dasar pembentuk 
karies gigi. Munculnya fenomena back to nature mengisyaratkan bahwa tanaman maupun tumbuhan di alam semakin penting peranannya. Perkembangan peranan tersebut perlu diperkuat dengan penelitian, baik secara kualitatif maupun kuantitatif untuk keamanan dan penggunaannya (Setiawan, dkk, 2016).

Salah satu tanaman yang memiliki aktivitas antibakteri terhadap $S$. mutans yang telah banyak diteliti adalah daun beluntas. Beluntas (Pluchea indica (L.) LESS. ). Flavonoid dalam daun beluntas memiliki aktivitas antibakteri, demikian juga senyawa fenol yang terkandung di dalamnya merupakan suatu alkohol yang bersifat asam sehingga disebut juga asam karbolat, yang mempunyai sifat antibakteri yakni menghambat pertumbuhan sel bakteri E. coli (Susanti, 2006).

Selain itu, penelitian yang dilakukan oleh Nahak Maria (2012) mendapatkan hasil bahwa ekstrak etanol daun beluntas dengan konsentrasi 25\%, telah dapat menghambat pertumbuhan bakteri S. mutans.

Akhi-akhir ini telah banyak terjadi eksploitasi bagian tanaman sebagai tanaman obat yang terus meningkat menyebabkan semakin berkurangnya sumber daya alam. Salah satu usaha untuk mengurangi eksploitasi tersebut adalah dengan mengisolasi jamur endofit pada bagian tanaman yang dapat memproduksi senyawa aktif.

Fungi endofit merupakan fungi yang hidup di dalam jaringan tumbuhan tanpa menimbulkan gejala penyakit pada tumbuhan inangnya. Fungi endofit mampu menghasilkan senyawa-senyawa bioaktif misalnya senyawa antibakteri, antifungi, antivirus, antikanker, antimalaria dan sebagainya (Strobel, 2003 dalam Prihatiningtias dkk, 2011).

\section{METODE PENELITIAN}

Jenis penelitian yang digunakan adalah penelitian eksperimen, dengan desain penelitian (RAL) rancangan acak lengkap. Penelitian ini dilaksanakan di laboratorium Mikrobiologi dan Parasitologi Akademi Farmasi Bina Husada Kendari. Sampel penelitian diperoleh dari Kota Kendari

\section{ALAT DAN BAHAN}

Alat yang digunakan Autoklaf (Mammert), Batang pengaduk, Cawan petri, Gelas kimia (Pyrex), Gelas ukur (Pyrex), Inkubator (Yenaco), Jangka sorong, Jarum ose, Kain flannel, LAF (laminar air flow), Lampu spiritus, Magnetic stirrer (HMS-79) Mikroskop, Mikropipet, Oven (Yenaco), Pingset, Piper disk, Centifuge (80-1), Shaker incubator 
(Health), Tabung reaksi (Pyrex) dan Timbangan analitik.

Bahan yang digunakan adalah Aquadest, Minosep (Chlorhexidine gluconate 0,1\%), Etanol 70\%, Kloramfenikol, Larutan $\mathrm{NaCl}$ 0,9 \%, media PDA (Potato Dextrose Agar)(Oxoid), Media PDY (Potato Dextrose Yeast) (Oxoid) media NA (Nutrient Agar)(Oxoid), $\mathrm{NaOCl} 5,25$ \% dan Daun beluntas.

\section{PROSEDUR KERJA}

\section{Pembuatan jamur endofit daun beluntas (Pluchea indica (L.) LESS.)}

Pengerjaan ini dilakukan di dalam LAF (Laminar Air Flow), pertama dilakukan Sterilisasi permukaan sampel dengan cara direndam di dalam etanol $70 \%$, dilanjutkan dengan ( $\mathrm{NaOCl} 5,25 \%)$ selama 3 menit lalu dibilas dengan aquadest steril. Dikecilkan ukurannya 1x1 cm lalu ditanam pada medium (PDA + Kloramfenikol) di dalam cawan petri steril lalu diinkubasi pada suhu kamar $\left(25^{\circ} \mathrm{C}\right)$ selama 7-14 hari. Setelah terjadi pertumbuhan fungi, lalu dipisahkan jamur hitam dan putih untuk mendapatkan biakan murni. Biakan murni fungi endofit ditumbuhkan pada media PDA dalam cawan petri.

\section{Pembuatan metabolit antibakteri jamur endofit daun beluntas}

Diambil satu ose jamur endofit dan ditumbuhkan pada medium PDY (Potato Dextrose Yeast) dalam erlenmeyer sambil digoyang goyangkan menggunakan shaker inkubator selama 14 hari lalu disentrifugasi dengan kecepatan 3800 rpm selama 20 menit. Supernatan diambil untuk digunakan dalam pengujian daya hambat.

\section{Pengujian Diameter Zona Hambatan}

\section{Jamur Endofit daun beluntas}

Pengujian diameter zona menggunakan metode Paper disk. Media kombinasi (PDA + NA) dipipet sebanyak $20 \mathrm{~mL}$ yang telah dicampur dengan suspensi bakteri uji $S$. mutans kemudian dituang kedalam cawan petri dibiarkan memadat. Dicelupkan masing-masing Paper disk ke dalam sampel pengenceran jamur endofit daun beluntas $10 \%, \quad 20 \%$ dan $30 \%$ lalu diletakkan pada permukaan media dan diatur jaraknya dan diinkubasi selama 1x24 jam pada suhu $37^{\circ} \mathrm{C}$ dalam incubator dan diukur luas daerah hambatan pertumbuhan bakterinya (Fauziah, dkk, 2018)

\section{Analisis Data}

Pengolahan data yang digunakan dalam penelitian ini adalah uji anova dilanjutkan uji BNT pada tingkat kepercayaan 95 ( $=0,05)$ dengan menggunakan SPSS 20 . 


\section{HASIL DAN PEMBAHASAN}

\section{Penyiapan sampel dan Isolasi Jamur}

\section{Endofit}

Daun beluntas dicuci bersih dengan air mengalir, agar semua kotorannya hilang. Sterilisasi permukaan sampel dengan cara merendam sampel dalam alkohol $70 \%$, kemudian $\mathrm{NaOCl} 5,25 \%$ dan dibilas dengan aquadest steril. Penggunaan alkohol 70\% dan $\mathrm{NaOCl}$ 5,25\% karena dengan konsentrasi tersebut efektif menghambat pertumbuhan bakteri. Medium yang digunakan saat isolasi yaitu medium PDA, karena medium ini berisi nutrisi yang dibutuhkan oleh jamur. Lalu ditambahkan kloramfenikol (PDAC), hal ini dilakukan untuk menekan pertumbuhan bakteri yang kemungkinan ikut tumbuh saat isolasi. Hasil dari isolasi jamur endofit pada ketiga replika setelah dilakukan pengamatan selama 14 hari dapat dilihat pada Gambar 1

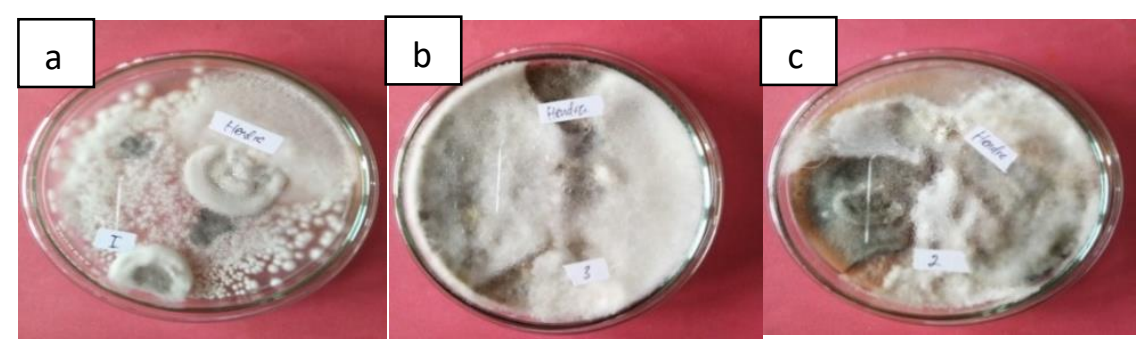

Gambar 1. Jamur endofit dari daun beluntas (Pluchea indica (L.) Less.) setelah inkubasi selama 2 minggu, (a) Replika pertama, (b) Replika kedua, (c) Replika ketiga.

\section{Karakterisasi Isolat Jamur Endofit}

Jamur endofit yang tumbuh di sekeliling daun beluntas dimurnikan (dipisahkan) hingga memperoleh isolat jamur endofit. Pemisahan ini berdasarkan warna dan pola pertumbuhan koloni jamur. Jamur endofit yang didapatkan hanya 2 jenis yaitu jamur endofit hitam dan endofit putih. Isolat jamur endofit dari daun beluntas yang telah murni selanjutnya dikarakterisasi untuk melihat ciri-ciri jamur secara makroskopik dan mikroskopik. Hasil isolasi jamur endofit dari daun beluntas dapat dilihat pada Gambar 7 

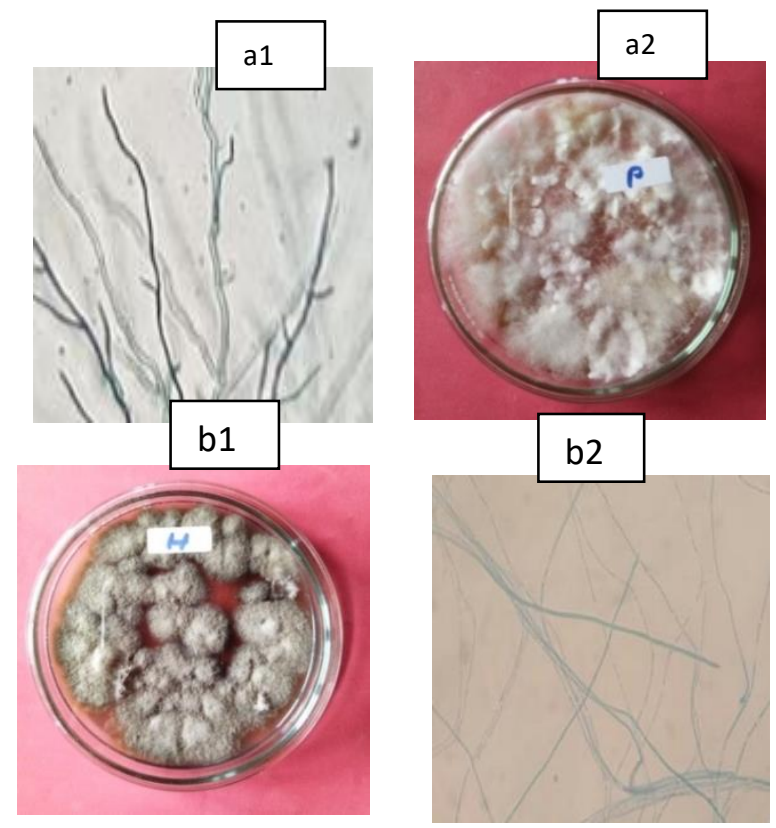

Gambar 1. Isolat Jamur Endofit daun beluntas (Pluchea indica (L.) Less.). Diperoleh duaisolat jamur endofit, yaitu (a1) Isolat Jamur Endofit Putih, (a2) Hasil pengamatan Mikroskopik Isolat Jamur Endofit Putih, (b1) Isolat Jamur Endofit Hitam, (b2) Hasil Pengamatan Mikroskopik Isolat Jamur Endofit Hitam.

Berdasarkan Gambar 7 dapat dilihat hasil isolasi jamur endofit dari daun beluntas (Pluchea indica (L.) Less.). Pengamatan makroskopik pada isolat jamur endofit putih terlihat koloni berwarna putih seperti kapas dan seperti serabut halus. Hasil pengamatan mikroskopik isolat jamur endofit putih memiliki hifa tidak bersekat (aseptat), konidiofor pendek dan konodia bersel satu. berdasarkan ciri-ciri tersebut jamur endofit putih diduga masuk kedalam spesies
Articulospora. Pada isolat jamur endofit hitam, koloni awalnya berwarna putih, lama-kelamaan bagian dasar koloni berubah warna menjadi hitam dan terlihat koloni berbentuk bulat. Hasil pengamatan mikroskopik isolat jamur endofit hitam memiliki bentuk hifa bersekat (septat) konidiofor bersel banyak dan konodia berbentuk bulat. ciri-ciri tersebut diduga menunjukkan jamur endofit hitam masuk kedalam spesies Geniculosporium, seperti gambar 2.
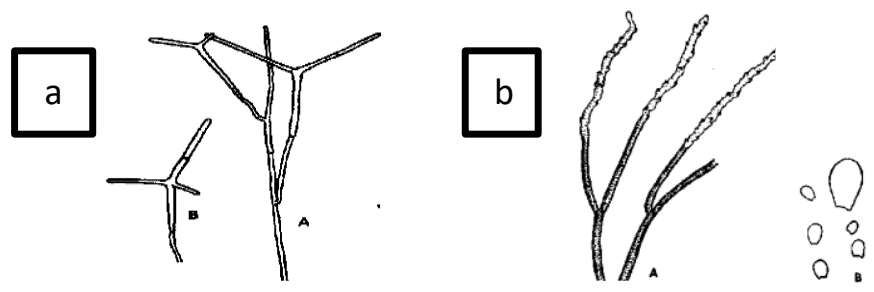

Gambar 2. (a) Articulospora, (b) Geniculosporium 


\section{Jamur endofit daun beluntas}

Setelah dipisahkan antara jamur endofit putih dan jamur endofit hitam, kemudian dilakukan proses fermentasi. Fermentasi dilakukan untuk memperoleh senyawa metabolit sekunder dari isolat jamur endofit. Media yang digunakan adalah media cair PDY (Potato Dextrose Yeast). Media PDY digunakan karena mengandung nutrisi yang dibutuhkan oleh jamur

\section{Metabolit sekunder antibakteri}

endofit. Jamur endofit yang difermentasi di dalam media cair PDY diaduk menggunakan shaker incubator selama 14 hari bertujuan agar media tersebar merata sehingga jamur endofit mendapatkan nutrisi yang cukup. Kemudian disentrifugasi agar endapan (pelet) dan supernatannya terpisah. Setelah terpisah supernatan ini yang akan digunakan dalam pengujian daya hambat.

\section{Hasil pengukuran zona hambat metabolit sekunder jamur endofit daun beluntas}

\section{terhadap bakteri S. mutans.}

Tabel 1. Data hasil penelitian jamur endofit putih

\begin{tabular}{|c|c|c|c|c|c|}
\hline \multirow{3}{*}{ Perlakuan } & \multicolumn{4}{|c|}{ Hasil zona hambat (mm) terhadap bakteri } & \multirow{3}{*}{$\begin{array}{c}\text { Rata-rata } \\
(\mathrm{mm})\end{array}$} \\
\hline & \multicolumn{3}{|c|}{ S. mutans } & \multirow{2}{*}{$\begin{array}{l}\text { Total } \\
(\mathrm{mm})\end{array}$} & \\
\hline & $\mathrm{I}$ & II & III & & \\
\hline $10 \%$ & 0,91 & 1,30 & 1,26 & 3,47 & 1,15 \\
\hline $20 \%$ & 1,16 & 1,70 & 1,68 & 4,45 & 1,51 \\
\hline $30 \%$ & 2,70 & 2,35 & 2,60 & 7,65 & 2,55 \\
\hline Kontrol (+) & 1,13 & 1,33 & 1,38 & 3,84 & 1,28 \\
\hline Kontrol (-) & - & - & - & - & - \\
\hline
\end{tabular}

Tabel 2. Data hasil penelitian jamur endofit hitam

\begin{tabular}{ccccccc}
\hline \multirow{2}{*}{ Perlakuan } & \multicolumn{2}{c}{ Hasil zona hambat (mm) terhadap bakteri } & & Total \\
& \multicolumn{4}{c}{ S. mutans } & II & Rata-rata \\
& I & II & III & & (mm) \\
\hline $10 \%$ & - & - & - & - & - \\
\hline $20 \%$ & - & - & - & - & - \\
\hline $30 \%$ & - & - & - & - & - \\
\hline Kontrol (+) & 0,70 & 1,20 & 1,65 & 3,55 & 1,18 \\
\hline Kontrol $(-)$ & - & - & - & - & - \\
\hline
\end{tabular}

Berdasarkan tabel 1. Jamur endofit putih memiliki daya hambat rata-rata pada konsentrasi $10 \%$ yaitu $1,15 \mathrm{~mm}, 20 \%$ yaitu $1,51 \mathrm{~mm}$ dan konsentrasi $30 \%$ yaitu $2,55 \mathrm{~mm}$ sedangkan kontrol positifnya 1,28 $\mathrm{mm}$. Menurut (Pan, dkk 2009) konsentrasi $10 \%, 20 \%$ dan $30 \%$ masih termasuk 
daya hambat dalam kategori lemah karena $<3 \mathrm{~mm}$ dan konsentrasi 20\% dan 30\% mempunyai daya hambat lebih tinggi dibandingkan kontrol positifnya. Sedangkan berdasarkan tabel 2. jamur endofit hitam tidak mempunyai daya hambat, hal ini diduga karena metabolit sekunder yang dihasilkan oleh jamur endofit hitam tidak sebanyak jamur endofit putih yang dapat menghambat bakteri $S$. mutans.

\section{KESIMPULAN}

Jamur endofit dari daun beluntas dapat menghambat pertumbuhan bakteri $S$. mutans. dengan zona hambat konsentrasi $10 \%$ yaitu 1,15 mm, 20\% yaitu 1,51 mm, 30\% yaitu 2,55 mm dan kontrol positifnya 1,28 mm. Sedangkan isolat jamur endofit hitam tidak dapat menghambat pertumbuhan bakteri $S$. mutans sedangkan rata- rata kontrol positifnya yaitu 1,18 $\mathrm{mm}$.

\section{DAFTAR PUSTAKA}

Daud, S, N, Desi, A,S, Ifaya, M, 2016, Formulasi Pasta Gigi Infusa Daun Jambu Biji (Psidium Guajava Linn) dengan Variasi Konsentrasi Na.CMC Sebagai Pengikat, Jurnal Ilmiah Ibnu Sina, 1(1) : 42 - 49

Fauziah, Y., Setiawan, M.A, Fitriani, 2018, Uji Daya Hambat Ekstrak Kerang Tahu (Meretrix meretrix)
Terhadap Bakteri Staphylococcus aureus, Jurnal Ilmiah Ibnu Sina, $3(1): 19-27$.

Lewis, D.W., dan Ismail, A.I. 1993, Dental Caris, Diagnosis, Risk Factors and Prevention. Can Med Assoc J. p.408-417.

Musdalipah, Setiawan, M, A, Santi, E.,2018, Analisis Efektivitas Biaya Antibiotik Sefotaxime dan Gentamisin Penderita Pneumonia pada Balita di RSUD Kabupaten Bombana Provinsi Sulawesi Tenggara, Jurnal Ilmiah Ibnu Sina, 3(1) : 1 - 11

Nahak, M.M. 2012, Ekstrak Etanol Daun Beluntas (Pluchea indica. L.) dapat Menghambat Pertumbuhan Bakteri S. mutans. Laporan Tesis. Program Pasca Sarjana Universitas Udayana Denpasar. Metodologi Penelitian Kesehatan, Rineka Cipta, Jakarta.

Susanti, A. 2006, Daya Anti Bakteri Ekstrak Etanol Daun Beluntas (Pluchea indica. Less) Terhadap Escherichia coli Secara in vitro. Fakultas Kedokteran Hewan Universitas Airlangga. Surabaya. p. 1-2.

Prihatiningtias,W., Widyastuti S.M., dan Wahyono, S. 2011, Aktivitas Antibakteri Fungi Endofit Thievalia polygonoperda, Isolat Dari Tumbuhan Akar Kuning (Fibraurea chloroleuca, Miers), Fakultas farmasi UGM.

Strobel G.A., and Daisy B. 2003, Bioprospecting for Microbial Endophytes and Their Natural Products. Microbiol. and Mol. Biology Rev. 67(4):491-502. 
Setiawan, A, M, Hasnawati, Sernita, Sulistia, L., 2016, Uji Daya Hambat Antibakteri Fungi Endofit Kulit Jeruk (Citrus Aurantifolia) terhadap Bakteri Staphylococcus aureus, Jurnal Sains Farmasi dan Klinis, 3(1) : 14 $-18$

Pan, X., Chen, F., Wu, T., Tang, H., and Zhao, Z. 2009. The acid, Bile Tolerance and Antimicrobial property of Lactobacillus acidophilus NIT. J. Food Kontrol 20 :598-602 